Department of Clinical Neuroscience

Sanna Graniittiaho

Study program in medicine KI

Degree project 30 credits

Spring 2020

\title{
Effects of sleep deprivation on empathy for pain and emotion regulation: A behavioral and neuroimaging study
}

\author{
Final version \\ Author: Sanna Graniittiaho
}

Supervisor: Gustav Nilsonne

\section{Karolinska Institutet}




\title{
Effekter av en natts sömnbrist på känsloreglering och empati: En beteende- och hjärnavbildningsstudie
}

\begin{abstract}
Bakgrund: Känsloreglering och empati påverkas av sömnbrist. Det är dock okänt ifall dessa effekter beror på minskad neural aktivitet i hjärnområden som reglerar dessa funktioner. I utvilat tillstånd orsakar kortikal hjärnaktivitet reglering av emotionella reaktioner och empati genom att reglera aktiviteten i amygdala. Neural aktivitet kan undersökas med funktionell hjärnavbildning (fMRI) Syfte: Den här studien syftade till att undersöka effekter av en natts sömnbrist på empati och känsloreglering via omtolkning. Vi hypotiserade att sömnbrist skulle leda till minskad kortikal aktivitet samt ökad aktivitet i amygdala, som tecken på minskad inhibitorisk signalering. Material och Metoder: 35 unga, friska försökspersoner genomgick funktionell magnetkameraundersökning (fMRI) efter en natt utan sömn och en natts rutinmässig sömn. Empati undersöktes beteendemässigt genom att jämföra självskattat obehag på smärtsamma bilder och icke smärtsamma bilder. Känsloreglering undersöktes genom att jämföra skattningar vid instruktion att nedreglera och att inte nedreglera upplevt obehag. Neural aktivitet under uppgiften undersöktes med fMRI. Resultat: Bilder på smärta skattades mindre obehagliga under sömnbrist än i utvilat tillstånd ( $\mathrm{p}<0.001)$. Effekten av omtolkning påverkades inte av sömnbrist. Sömnbrist påverkade inte heller fMRI-signalerna i de undersökta kortikala områden signifikant. Aktiviteten i amygdalae var ökad under sömnbrist, dock icke-signifikant $(\mathrm{p}=0.13)$. Slutsats: Den empatiska reaktionen på smärtsamma bilder var nedsatt under sömnbrist, som hypotiserat. Däremot påvisades ingen skillnad i förmågan att omtolka. Sömnbrist ledde inte till sådana förändringar i hjärnaktivitet som skulle stödja hypotesen om minskad inhibitorisk kortikal aktivitet.
\end{abstract}

Nyckelord: sömnbrist, empati, känsloreglering, omtolkning, funktionell hjärnavbildning

\section{Effects of sleep deprivation on empathy for pain and emotion regulation: A behavioral and neuroimaging study}

Introduction: Emotion regulation and empathy are affected by sleep deprivation. Whether these effects are caused by changes in neural activity in regions regulating the functions is unknown. When wellrested, cortical activity regulates emotional reactions and empathy by decreasing activity in the amygdalae. Neural activity can be measured with functional magnetic resonance imaging (fMRI). Aim: The aim of this study was to investigate the effect of one night of sleep deprivation on empathy for pain and emotion regulation through cognitive reappraisal, that is, intentional downregulation. We hypothesized that sleep deprivation would lead to decreased cortical activity and increased activity in amygdalae. Material and Methods: 35 healthy, young participants underwent fMRI after one night of sleep deprivation and one night of habitual sleep. Behaviorally, empathy was assessed by comparing self-reported unpleasantness between painful images and non-painful images, and reappraisal was investigated by comparing unpleasantness between instructions to downregulate and maintain. fMRI was performed to measure neural activity during the task. Results: Participants reported less unpleasantness when viewing painful images when sleep-deprived $(\mathrm{p}<0.001)$. Sleep deprivation caused no decrease in ability to reappraise, nor did sleep deprivation cause decrease in cortical fMRI-signals. Activity in the amygdalae was non-significantly increased in sleep-deprived condition $(\mathrm{p}=0.13)$. Conclusions: As hypothesized, the empathic response to pictures of pain was decreased during sleep deprivation. However, no decrease in ability to reappraise was found. Sleep deprivation did not cause changes in neural activity that would support our hypothesis of decreased inhibitory cortical activity.

Keywords: sleep deprivation, empathy, emotion regulation, cognitive reappraisal, functional brain imaging 

Abbrevations
AI
Anterior Insula
aMCC
Anterior midcingulate cortex
BOLD
Blood Oxygen Level Dependent
Coi
Conditional One Inflation
dIPFC
Dorsolateral prefrontal cortex
fMRI
Functional magnetic resonance imaging
IOFC
Lateral orbitofrontal cortex
MRI
Magnetic resonance imaging
NREM Non-rapid eye-movement
PFC
Prefrontal Cortex
REM Rapid eye movement
ROI Region of interest
SB1 Stockholm Sleepy Brain Project 1
SB2
Stockholm Sleepy Brain Project 2
Zoi
Zero-one inflation
ZOIB
Zero-one-inflated beta 


\section{Background}

Sleep deprivation has both psychological and physiological consequences. Among the first affected functions are emotional functions, such as emotion regulation end empathy $(1,2)$. During sleep deprivation, the ability to regulate emotions and to experience empathy are decreased (3, 4). Emotion regulation and empathy are needed for mental health, making the effects of sleep deprivation have impact on both an individual and a societal level $(5,6)$. Despite the vast impact that sleep deprivation can have, knowledge on neural mechanisms of sleepiness remains deficient.

\section{Sleep deprivation and sleepiness}

In the modern world with countless sources of stimulation keeping an individual awake past bedtime, the prevalence of sleep deprivation is high. According to general guidelines, a minimum of 6-8 hours a day should be spent asleep (7). However, despite recommendations, the percentage of people who reported less than 6 hours of sleep per night in the US in 2014 was $30-40 \%$ (8). Likewise, a Swedish study conducted in 2019 showed that 55\% of Swedish adolescents slept less than the recommended 8 hours per night (9).

Insufficient sleep is thus common in several countries and age groups. Not reaching the needed hours of sleep leads to sleepiness, that is, the urge and tendency to fall asleep. Sleepiness consist of two components: the homeostatic and circadian sleep drives (10). The homeostatic drive is related to the neurochemical mechanism of sleep. During time awake, substances like adenosine build up in the brain tissue (10). Sleep is thought to reverse this build-up, restoring neural homeostasis that is required for wakefulness and vigilance (10). The second sleepinessregulating mechanism is the circadian rhythm. It is a biological clock-mechanism that detects circadian changes in the environment and mediates sleepiness through several mechanisms, one of which is the secretion of melatonin (10).

Sleep can be divided into two main stages: rapid eye movement sleep (REM) and non-rapid eye movement sleep (NREM) (10). During a night of sleep, the stages occur in repeated cycles. The REM/NREM-ratio increases towards the end of the night. Different sleep stages serve unique functions, making the effect of sleep loss depend on which stage of sleep is restricted (11-13) . 


\section{Functional imaging of the brain}

Since sleepiness arises from neural changes, brain imaging provides a method for studying effects of sleep deprivation. Functional magnetic resonance imaging (fMRI) is one modality for imaging neural activity. Blood flow in a region reflects the need of nutrient supply and therefore correlates with neural activity (14). It is possible to visualize blood flow with fMRI since the scanner detects Blood Oxygen Level Dependent (BOLD) Signals. The signal is based on oxygenated and deoxygenated hemoglobin having different magnetic properties, which allows the visualization of blood flow from the arterial to the venous system (14).

\section{Emotions}

Like sleepiness, emotions arise from neural activity and can be studied using fMRI (15). Emotions are created in the limbic system. For generating negative emotions, such as unpleasantness, the amygdala plays a key role in the generation of an emotion (16). After generation, an emotion goes through cortical processing. Theories on emotion propose different models for how emotions are cortically processed. The models can be divided into discrete and dimensional (17). Ekman's theory of emotion divides emotions into discrete emotions, such as fear, sadness, anger and happiness. According to the theory, each of these emotions are caused by activity in their unique neural networks (18). However, a subjective experience of an emotion seldom is discretely categorizable, which is one reason for the criticism of discrete theories (17). Dimensional models, such as Feldman Barrett's theory of constructed emotion, suggest that emotions are a sum of activity in several neural networks, unique to each context (17).

Despite the criticism of discrete models, in neuroimaging studies emotions are generally treated as discrete categories. By provoking a theoretical emotion while performing fMRI, cortical regions with increased activity can be identified (19). This can, for example, be achieved by presenting pictures to an investigated person in the MR-scanner. Neural activity in a region correlates with intensity of an experienced emotion and knowledge of theoretical location of emotion is a useful tool in research.

\section{Emotion regulation}

In addition to varying in character, emotions can vary in intensity. Intensity of an emotion can be regulated through intentional effort to do so. When an emotion is intentionally modulated, 
areas in the frontal cortex are recruited to regulate activity generated in the limbic system. This regulatory activity is possible due to functionally connected inhibitory neural networks between cortical areas and the limbic system (20). For negative emotions, such as unpleasantness, a key functionally connected pathway is between the prefrontal cortex (PFC) and the amygdala (20). Cognitive reappraisal (see below) is an emotion regulation method that recruits this inhibitory network. An emotion response is created in several steps and the step that cognitive reappraisal modulates is illustrated in Figure 1 (21).

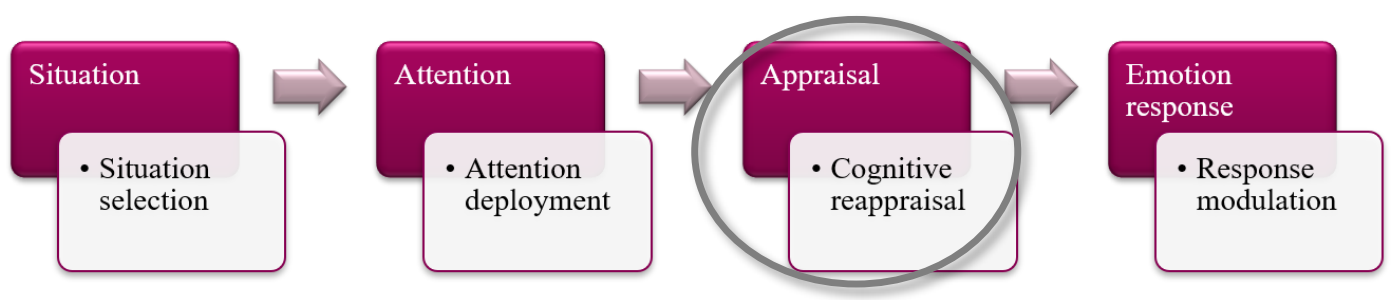

Figure 1: Emotion generation process and emotion regulation methods. Plum boxes: emotion generation process. White box: Emotion regulation method. Cognitive reappraisal is a method that changes how a stimuli is appraised.

Cognitive reappraisal means that an emotion is intentionally up- or downregulated (21). An initial appraisal is a result of the brain interpreting stimuli without active cognitive input. An active effort to re-evaluate the stimuli can change the emotion - the emotion is re-appraised (21). For example, unpleasantness caused by a picture of pain can be reappraised through thinking "This is a scene in a picture, there is therefore no reason for me to feel bad about it". Cognitive reappraisal is one of the most effective techniques for emotion regulation, especially for emotions caused by external cues and thus in experimental settings (21).

Cortical regions active when reappraising are the dorsolateral prefrontal cortex (dlPFC) and lateral orbitofrontal cortex (1OFC) (22). During reappraisal, inhibitory signals from these areas decrease activity in the amygdala and therefore decrease the negative emotion response (20). Why sleep deprivation impairs emotional functions, such as emotion regulation and empathy, is yet unknown. A proposed theory is that sleep deprivation disconnects connectivity between cortical and limbic structures, decreasing inhibitory signaling from the PFC to the amygdala $(23,24)$. This in turn leads to increased activity in the amygdala, as illustrated in Figure 2. 

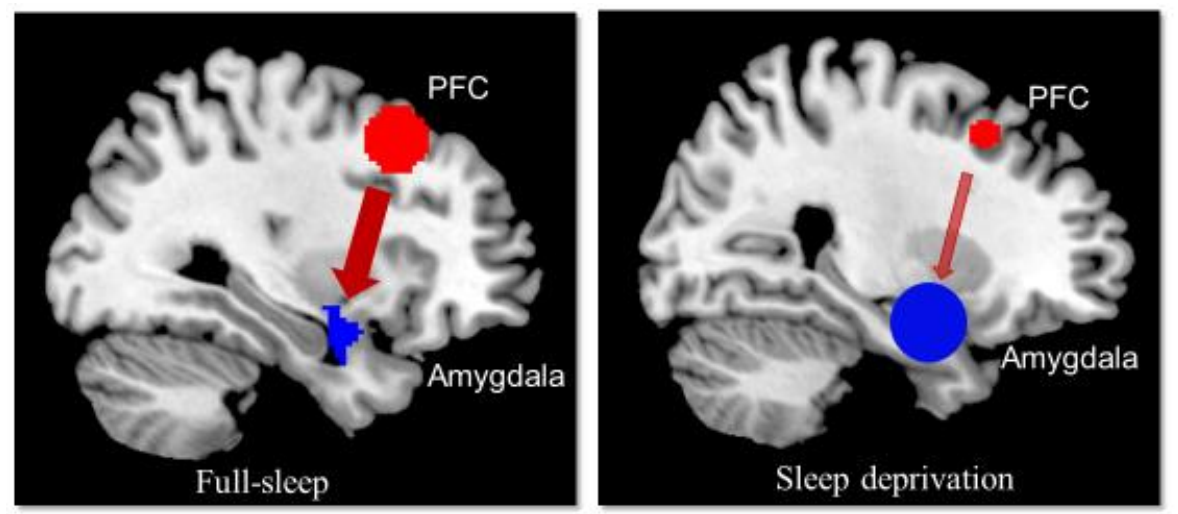

Figure 2: Hypothesized effect of sleep deprivation on inhibitory signaling from the cortical areas to the amygdala: decreased inhibitory signaling during sleep deprivation. $\mathrm{PFC}=$ Prefrontal cortex. The arrow represents inhibitory signaling. Size of a region represent activity. (Sanna Graniittiaho)

\section{Empathy}

In addition to decreasing ability to regulate emotions, sleep deprivation has been proposed to affect empathy. Empathy can be defined as the ability to share someone else's emotions by imaging what it would be like to be in that persons' situation, combined with an awareness of the source of the emotion being external (25). These two components of empathy can be categorized as cognitive and emotional. Cognitive empathy includes understanding another's emotion, whereas emotional empathy includes sharing and experiencing the emotion. For example, unpleasantness caused by a picture of pain is an emotional empathic response (26). Cortical areas active when viewing pictures of pain are the anterior insula (AI) and the anterior midcingulate cortex (aMCC) (25). Similar to when it comes to reappraisal, these cortical regions are where the empathic response is processed.

\section{Sleep, emotional functions and mental health}

In summary, the regions central in empathy and cognitive reappraisal are the AI, aMCC, dlPFC, IOFC and the amygdala. Sleep is crucial for these regions to function optimally. Regions associated with emotional functions are highly active during REM sleep (11-13). Furthermore, lack of REM-sleep leads to impaired emotional memory formation, which indicates cruciality of REM-sleep for emotional recovering (11-13). However, the neural underpinning behind the loss of emotional functioning during sleep deprivation is yet unknown.

Since sleep deprivation has emotional effects, it also has impact on mental health. Several mental disorders are associated with sleep disturbances. In fact, most affective disorders cooccur with insomnia (27). Sleep deprivation as itself also has potential causal effects on mental health. Depression, anxiety, obsessive compulsive disorder and phobias all include decreased 
ability to regulate emotions $(5,6)$. Moreover, lacking ability to regulate emotions has been shown to correlate positively with mental health issues $(5,6)$. Since sleep deprivation decreases ability to regulate emotions, the potentially harmful cause-effect relationship makes the emotional effects of insufficient sleep clinically relevant.

\section{Previous studies}

\section{Behavioral studies}

Emotion-related effects of sleep deprivation have been investigated in behavioral studies. Sleep deprivation causes neutral stimuli to be perceived as more negative and the ability to cognitively regulate emotions is decreased $(3,4)$. The biggest effect has most consistently been detected in ability to downregulate negative emotions (28). For example, when participants were instructed to cognitively reappraise responses caused by negative stimuli, those who were sleep-deprived were significantly less effective in downregulating their negative emotional response (29). However, not all studies have reached similar conclusions. Some studies have not detected decreased ability to regulate emotional response, but the authors have suggested that participants were not subjected to severe enough sleep deprivation (30).

Furthermore, empathic responding has been investigated in behavioral studies as well. Several authors have reported that empathic responses are weaker during sleep deprivation $(31,32)$. Decreased empathic responding due to sleep deprivation has been detected in measures of both emotional and cognitive empathy (31). For example, Guadagni et al reported that participants experienced negative pictures as less negative when they were deprived of sleep (32). However, some studies also show contradictory results. Tamm et al reported no detectable decrease in empathic responding to pictures of pain after a night of restricted sleep (33). Even though not all behavioral studies show similar results, it has been proposed that both emotion regulation and empathy are affected when an individual is severely sleep deprived (34).

\section{Imaging studies using fMRI}

Behaviorally detected changes raise questions about underlying neural mechanisms. In neuroimaging studies conducted so far, results have not fully supported the hypothesis of decreased inhibitory signaling. As hypothesized, the amygdala has in several studies been significantly more active in the sleep deprived brain. For instance, Yoo et al reported increased amygdala activity in participants in the sleep deprived condition (16). Moreover, Yoo et al 
reported decreased amygdala-PFC connectivity as a response to negative stimuli. Their finding generated the hypothesis that decreased connectivity might be the causal factor behind behaviorally detected effects.

Contradictory results have been reported in fMRI-studies where the aim has been to investigate the hypothesis by measuring task-related cortical activity, with the expectation that cortical activity decreases when an individual is deprived of sleep. Minkel et al (35) investigated the effects of sleep deprivation on emotion regulation through cognitive reappraisal, but found no significant decrease in activity in the dlPFC or the 1OFC. Similarly, neither Tamm et al (36) or Shermohammed et al (37) detected a significant decrease in cortical activity in participants who were deprived of sleep.

Furthermore, as with emotion regulation, regions associated with empathy are hypothesized to be less active during sleep deprivation. The effect of sleep deprivation on empathy has been studied using fMRI by Tamm et. al. and Guadagni et al. No decrease in activity in the AI or the aMCC was detected when Tamm et al (33) restricted participants' sleep to 3 hours. However, Guadagni et al (38) found that AI activity was lower in those who rated bad quality of sleep, which supports the hypothesis.

In conclusion, studies up to date did not provide results showing hypothesized or consistent changes in neural circuits of emotion, which would have been increased activity in the amygdala and decreased cortical activity. Previous studies are few and several of them have been conducted on partially sleep-deprived individuals. Further research where participants are subjected to more severe sleep deprivation is therefore indicated. One of the few studies conducted using fMRI is the study by Tamm et al, also called the Stockholm Sleepy Brain Project 1 (SB1) $(33,36)$. Continuing the work of SB1, The Stockholm Sleepy Brain Project 2 (SB2) aims to research the questions further, with more severe sleep deprivation. This degree project is a part of SB2 and focuses on the emotional aspects of the study; emotion regulation and empathy. 


\begin{abstract}
Aims
This study aimed to behaviorally and with neuroimaging investigate effects of one night of total sleep deprivation on empathy for pain and emotion regulation through cognitive reappraisal. A specified aim was to investigate whether findings indicating decreased cortical inhibitory signaling to the amygdala would be detected in areas associated with emotion regulation and likewise those associated with empathy.
\end{abstract}

\title{
Hypotheses
}

We hypothesized that pictures of pain would activate neural circuits associated with empathy for pain: the AI and the aMCC. We also hypothesized that an instruction to downregulate this unpleasantness would activate cortical regions associated with emotion regulation through cognitive reappraisal: the dlPFC and 1OFC. Moreover, we hypothesized that in the sleepdeprived condition, inhibitory signaling between cortical regions and the amygdala would be decreased. This would be detected as increased activity in the amygdala and decreased activity in the associated cortical regions.

Behaviorally, decreased empathic responding was expected to be detected as decreased selfrated unpleasantness to pictures of pain during sleep deprivation. We also expected that decreased ability to regulate emotional responses would be detected as higher rated unpleasantness after an instruction to downregulate in the sleep deprived condition, in comparison with ratings in the well-rested state.

\section{Material and methods}

\section{Study design}

This was an experimental study with two intervention nights. In total, each participant underwent three imaging sessions. The first session was to acquire structural images and to rule out anatomical abnormalities. The second and the third sessions were conducted in a withinsubject crossover design either after a habitual night of sleep at home or after a night of sleep deprivation. Approximately one month was scheduled between the two intervention nights and the order of them was randomized. The sleep deprivation night was carried out at the Stockholm University sleep lab, where participants were supervised in a hyper-illuminated room to ensure them not falling asleep. Low-intensity activities such as socializing, watching TV, eating and gaming were allowed. No caffeine or other stimulants were allowed to be consumed during the 
experimental 24 hours. The imaging sessions were carried out during the morning after the intervention nights, starting at 7.30 AM and ending at 11.00 $\mathrm{AM}$ at latest.

\section{Participants}

Participants were recruited through studentkaninen.se and posters at university campuses in Stockholm. A total of 35 participants who fit the inclusion and exclusion criteria (see below) participated, 9 of which during a pilot run of the same project. All participants were between 20 and 35 years old, with a mean age of 26.14 of them were female and 21 were men. Participant flowchart for the main study is presented in figure 3.

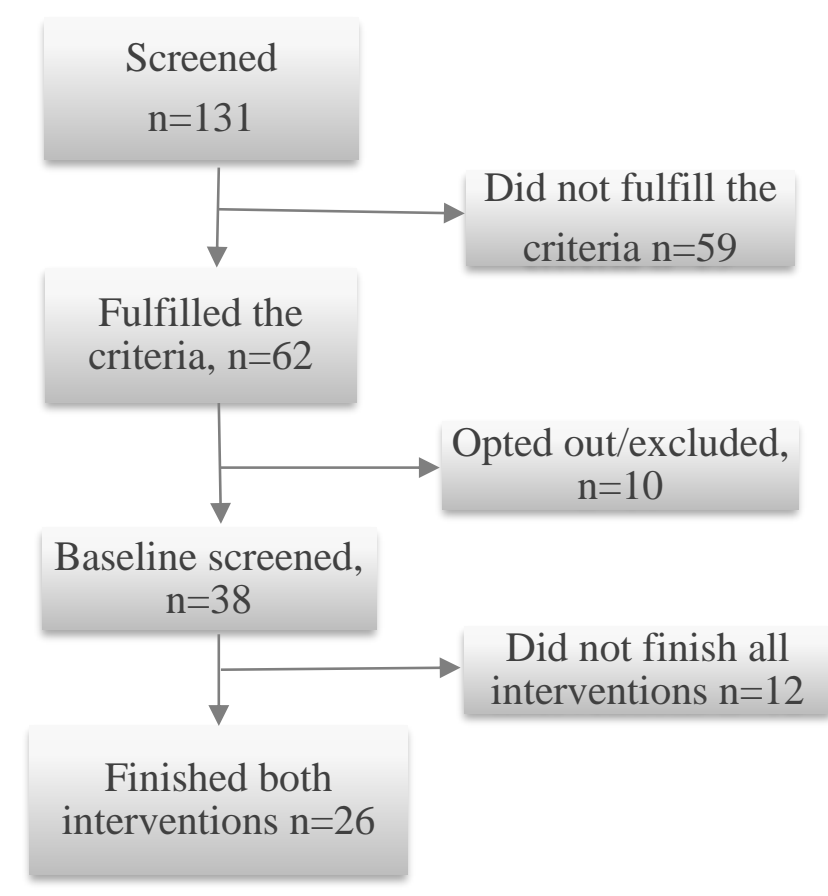

Figure 3: participant flowchart in the main study.

\section{Inclusion and exclusion criteria}

To be included, participants were required to be healthy, around 20-30 years old, right-handed, fluent in Swedish language, to have good visual acuity and to have habitual bedtime between 22 PM and 01 AM on weekdays. Exclusion criteria included studies or work within healthcare, having diabetes, mental disorders or high blood pressure, consumption of over 4 cups of coffee a day and daily nicotine use. Having claustrophobia, ferromagnetic objects in the body and being pregnant were exclusion criteria due to risks of the magnetic field of the MR-scanner. 


\section{Experimental methods}

\section{Experimental methods: empathy}

Empathy was investigated by comparing self-reported unpleasantness between painful images and non-painful images, since unpleasantness caused by pictures of pain can be interpreted as empathic unpleasantness. The picture set included neutral pictures and pictures of pain in a randomized order. After each picture, participants rated their perceived unpleasantness on a 0 - 100 visual analogue scale. Participants performed this by choosing a point on a 0 to 100 line. The pointer moved when pressing buttons on a hand-held response box. The scale is illustrated in Figure 4 and was presented on a screen in the scanner.

\section{Experimental methods: emotion regulation through reappraisal}

Emotion regulation was investigated by comparing unpleasantness ratings between instructions to downregulate and to maintain unpleasantness. Unpleasantness was stimulated by presenting pictures of pain. The picture set included 48 pictures in total, 16 of which were a combination "maintain pain", 16 "downregulate pain" and 16 "maintain neutral". The duration of the entire task was approximately 15 minutes. Before going into the scanner, participants were instructed to either spontaneously experience the emotion caused by the picture or to intentionally aim to downregulate the emotion, depending on which instruction the presented arrow indicated. Prior to starting the experiment, we asked and ensured that each participant had understood the task. Afterwards, participants were asked to report exactly what method they had used in order to downregulate. A schematic illustration in of the task is in Figure 4.

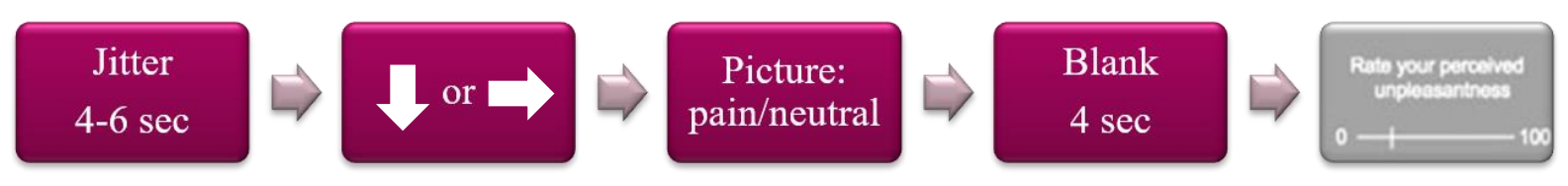

Figure 4: Schematic illustration of the experimental method. Arrow down: downregulate. Arrow towards right: maintain.

\section{MR-scanning}

We used a 3T GE Discovery 750 MRI scanner. Structural baseline images were acquired using a T1-weighted scan in axial plane with 180 slices. Functional scans were acquired with interleaved acquisition with 40 slices, $3 \mathrm{~mm}$ thickness and $0,5 \mathrm{~mm}$ spacing. The repetition time 
was 2 seconds. Preprocessing of fMRI-data was done in the fMRIprep -software and included slice time correction, realignment, co-registration, normalization and smoothing.

\section{Statistical methods}

Behavioral aspects based on unpleasantness ratings were investigated using mixed-effects regression. Main effects of stimulus type, instruction and sleep deprivation were investigated in the R software (version 3.6.2) with the nlme package. Interactions between sleep deprivation and stimulus type and instruction, respectively, were also investigated. Significance level was defined as $p<0.05$ and results are reported in effect estimates with $95 \%$ confidence interval, as (estimated mean in rated unpleasantness $[95 \% \mathrm{CI}], p$ ).

The dataset included a relatively large number of ratings of 0 (1045 out of 3072) and inspection of the residuals of the linear mixed-effects model show a deviation from normality due to the floor effect. To investigate accuracy of the model in analyzing non-normally distributed data, analysis was also done using zero-one-inflated beta (zoib) -regression, as described by Vuorre (39). The zoib -model adds a separate discrete process for ratings of 0 and 1 , or 100 in the case of our study, using two additional parameters. It can therefore be preferable to use in combination with the linear model when analyzing data with datapoints clustered at 0 or 100 , as often occurs when using a visual analogue scale. The zoib -analysis was done using the brms package in R, which implements Bayesian mixed-effects models.

fMRI-data were analyzed using the general linear model. Main effects were defined as pain vs no pain for empathy and downregulate vs maintain for reappraisal, respectively. T-contrasts were generated for the main effects from each session. At second level, $t$-tests were performed to investigate main effects and the effect of sleep deprivation. This was done using the nlme package in the $\mathrm{R}$ software. The amygdala, AI, aMCC, dIPFC and 1OFC were used as predetermined regions of interest to analyze effect. $p<0.05$ was considered statistically significant.

\section{Ethical considerations}

Participation in this study was voluntary and participants were informed and consented before participation. It was possible to withdraw at any moment during the study, with no need to specify a reason. Participants were paid 1500 SEK for participating, even in the case of 
withdrawal. The exclusion criteria ruled out participants with risk of negative outcome from participation. Due to an increased risk for traffic accidents when sleep-deprived (40), participants were offered taxi drives from the sleep lab. Participation was not expected to cause any harm besides temporary sleepiness, which is comparable with a badly slept night in the daily life. Permanent effects of sleep loss require chronic exposure. The potential benefits of gaining knowledge on mechanisms of sleep deprivation likely outweigh the risks included.

There is a risk of incidental findings when imaging healthy participants with any modality. Baseline images were analyzed by a radiologist and in the case of incidental findings, further investigation would have been initiated. Since a majority of incidental findings are benign, an investigation process would likely result in unnecessary stress for the participant. On the other hand, if a finding turns out to be treatment-requiring, participation in an imaging study would result in treatment at an early stage. Participants were informed about the risks and consequences of incidental findings.

During ongoing data collection, the COVID-19-pandemic broke out. Due to a risk of spreading the virus in physical contact with participants, data collecting was ended earlier than planned. Ethical permit is required and exists from the Ethical Review Board in Stockholm, Sweden. Ethical review number: 2012/1098-31/2.

\section{Results}

\section{Behavioral results}

Behavioral results were based on unpleasantness ratings. Three significant effects were found: Firstly, negative stimuli caused a significant increase in unpleasantness ratings (18.47 [16.92, 20.03], $p<0.001$ ), as expected. Secondly, sleep deprivation caused increased unpleasantness ratings as a response to neutral stimuli (4.19 [2.59, 5,79], $p<0.001)$. Lastly, unpleasantness as a response to pictures of pain was significantly decreased in sleep deprived state (-5.26 [-8.36, $-2.16], p<0,001)$. An instruction to downregulate emotional response had no significant effect on rated unpleasantness $(-0.37[-1.92,1.17], p=0.64)$. In the sleep deprived condition, the effect of downregulation of unpleasantness was not significantly changed $(-2.49[-5.59,0.61]$, $p=0.12$ ). Unpleasantness ratings in the two conditions are presented in Figure 5 (see below). 


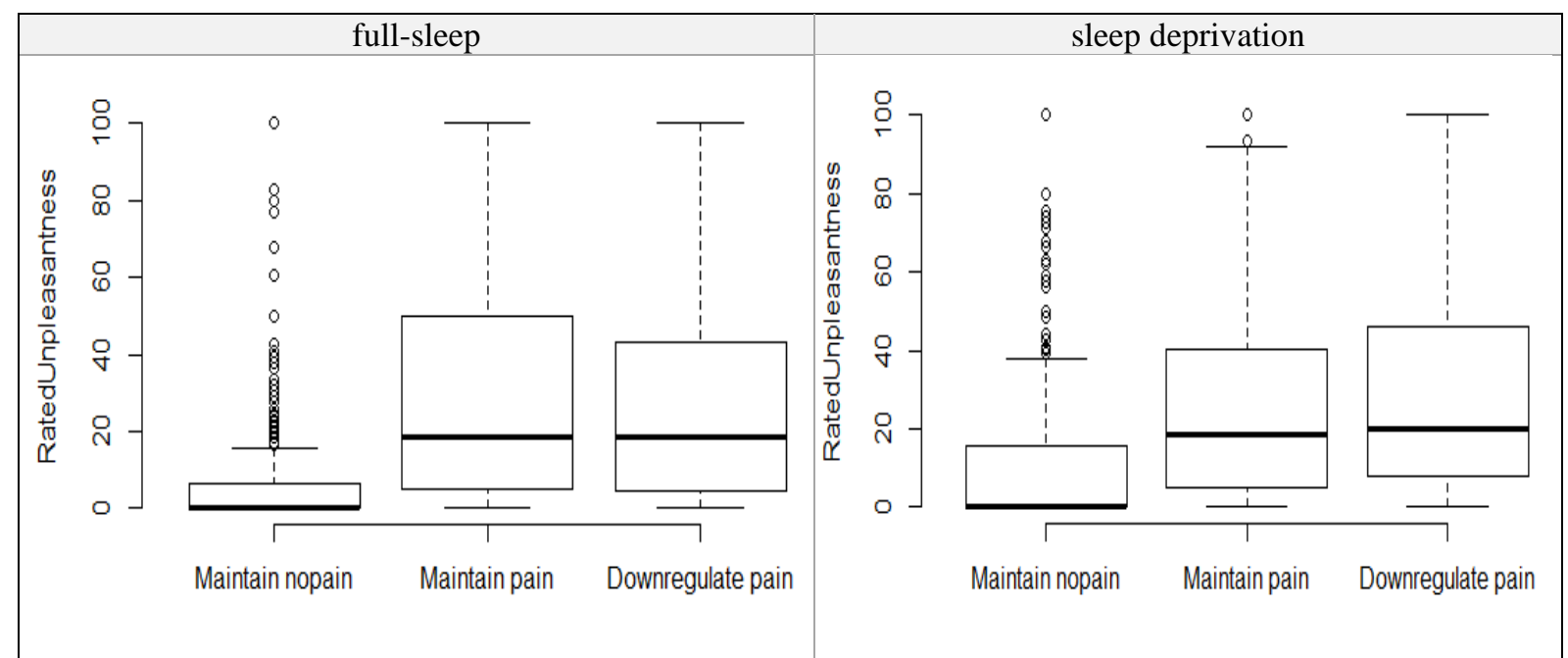

Figure 5: Unpleasantness ratings in full-sleep and sleep deprived condition. Boxplots of ratings on the $0-100$ scale in respective condition. Number of ratings, $n=3072$. No-pain, i.e. neutral, stimuli were rated more unpleasant during sleep deprivation $(\mathrm{p}<0.001)$, and painful stimuli as less unpleasant $(\mathrm{p}<$ $0.001)$. No significant effect of downregulation was detected in either condition.

According to self-reported information, approximately $20 \%$ of the participants did not succeed in performing cognitive reappraisal. To examine how these non-compliant individuals affected the results, analysis was also done separating these two groups. There was a non-significant trend among those who claimed that they reappraised to rate the painful images as less unpleasant when an instruction to downregulate was given $(-1.71[-3.91,0.47], p=0.12)$. Among those who self-reportedly did not reappraise, there was no decrease in unpleasantness ratings when instructed to downregulate $(1.25[-1.52,4.03], p=0.64)$. Similar to results without excluding the non-compliant individuals, sleep deprivation caused no significant decrease in ability to downregulate among the compliant individuals $(-2.75[-7.13,1.63], p=0.22)$

Comparison of linear mixed effects regression and zoib -regression provides a method for examining how deviation from normal distribution affects the results (39). Results using zoib regression are presented in table 1.

Table 1: Results using zoib-regression. $m u$ : estimate of unpleasantness rating in the continuous process. Zoi: represents the probability of a rating being 0 or 100 . Coi represents the probability of a rating being 100, given it is either 0 or 100 . Bold text when 0 not included in $95 \% \mathrm{CI}$

\begin{tabular}{|c|c|c|c|c|c|c|}
\hline & \multicolumn{2}{c}{ mu } & \multicolumn{2}{c|}{ zoi } & \multicolumn{2}{c|}{ coi } \\
& estimate & CI & estimate & CI & estimate & CI \\
\hline stimulus: pain & $\mathbf{1 5}$ & $\mathbf{1 2 , 1 8}$ & $\mathbf{- 0 . 3 2}$ & $\mathbf{- 0 . 4 3 , - 0 . 2 2}$ & $\mathbf{0 . 0 4}$ & $\mathbf{0 . 0 , 0 . 1 9}$ \\
\hline $\begin{array}{c}\text { instruction: downregulate } \\
\text { condition: sleep deprivation }\end{array}$ & 0.0 & $-0.1,0.1$ & 0.02 & $-0.03,0.08$ & 0.0 & $0.0,0.0$ \\
\hline $\begin{array}{c}\text { sleepdeprivation* } \\
\text { downregulate }\end{array}$ & -1.0 & $-3.0,2,0$ & 0.08 & $-0.04,0.21$ & 0.0 & $0.0,0.0$ \\
\hline sleep deprivation*pain & $\mathbf{- 5 . 0}$ & $\mathbf{- 8 . 0 , - 2 . 0}$ & $\mathbf{0 . 1 6}$ & $\mathbf{0 . 0 5 , 0 . 2 8}$ & 0.0 & $0.0,0.02$ \\
\hline
\end{tabular}


There are two components in the results of zoib-regression: one continuous and one discrete. $M u$ represents the estimated value in the continuous process. Zoi (zero-one-inflation) and coi (conditional one inflation) are the two parameters for the discrete process for ratings of 0 and 1 , or in the case of this study, 100. Zoi represents the probability of a value being either 0 or 100. Given that a value is 0 or 100, Coi represents the probability of a value being 100 and hence indicates higher probability of a stimulus being perceived as highly unpleasant. Positive coi therefore reinforces a result of higher unpleasantness in the continuous process, as in stimulus: pain. A combination coi zero and positive zoi represents higher probability of a rating being 0 , which indicates milder perceived unpleasantness and reinforces a result of decreased unpleasantness in the continuous process, as seen in the interaction sleep deprivation*pain. Negative zoi and coi zero, as seen in the effect of sleep deprivation, indicates that ratings were less likely to be 0 or 100 , i.e. participants experienced increased unpleasantness. They gave ratings higher than 0 but not to the extreme, 100. The zoib-results are consistent with those of mixed effects regression. Interactions between $m u$, coi and zoi, as discussed above, support the results (see Table 1).

\section{fMRI: neural activity related to reappraisal and empathy}

Main effects and the effect of sleep deprivation were analyzed in the predetermined ROIs, which are illustrated in Figure 6. Activity in these ROIs represent activity related to emotion regulation and empathy.

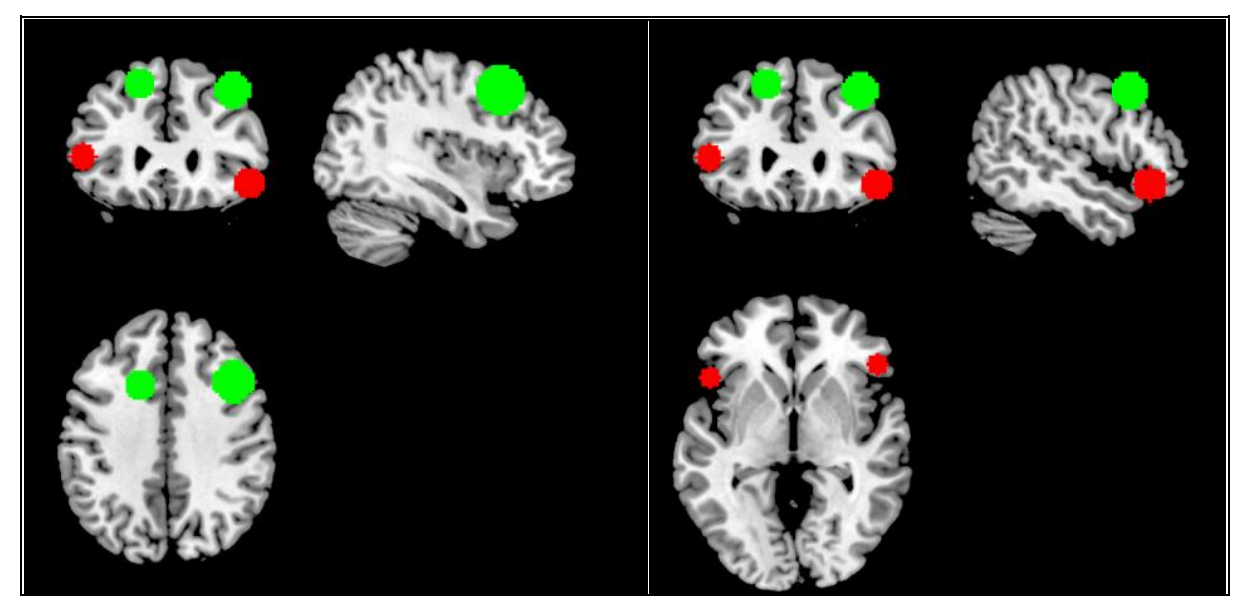




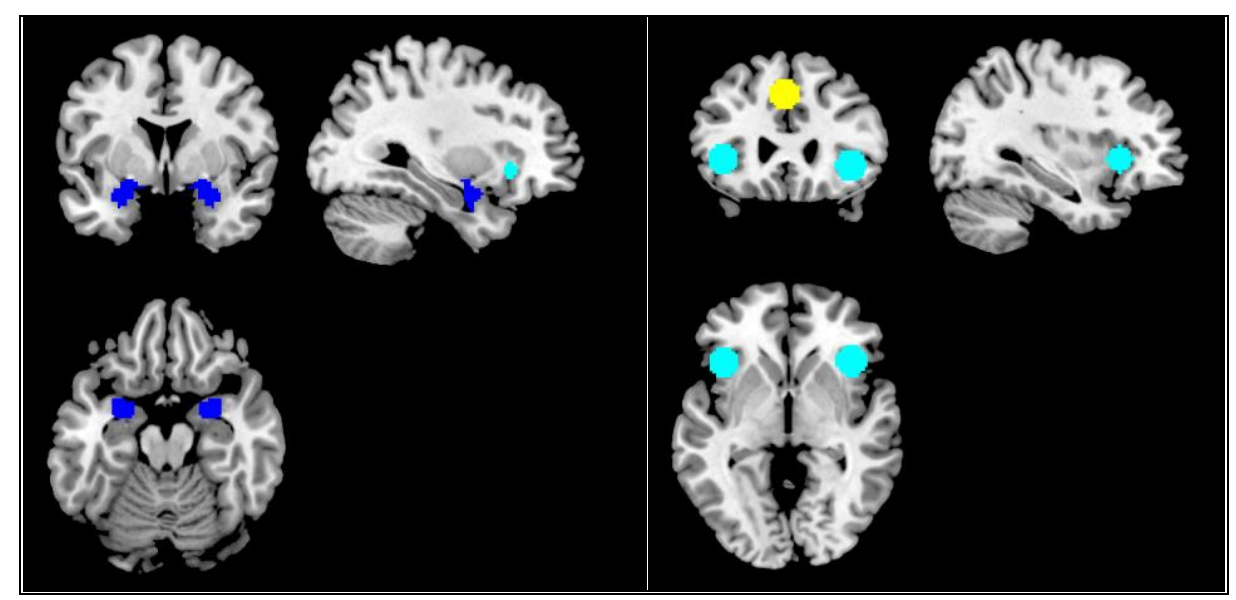

Figure 6: Regions of interest (ROIs) used in analyzing effect. Activity in these illustrated regions represent activity related to emotion regulation through reappraisal and empathy. Color codes for each ROI are the same for both left and right hemisphere. ROIs for reappraisal: Green $=d l P F C$, red $=l O F C$, dark blue $=$ amygdala . ROIs for empathy: light blue $=A I$, yellow $=m A C C$. The regions are illustrated on the MNI192 template using MRIcon. (Sanna Graniittiaho)

Analyses of fMRI-signals in these ROIs were done using the general linear model. Main effects represent the effect of the experimental method. Results investigating main effects and the effect of sleep deprivation on fMRI-signals are presented in Table 2. No statistically significant results were detected. However, two statistically non-significant findings were made, which show trends towards hypothesized changes in activity (see bold text in Table 2). First, pictures of pain resulted in a borderline significant activation of the ROIs for empathy; the AI and the aMCC, which indicates that the experimental method caused activation in the desired regions. Second, activity in the amygdalae was increased in the sleep deprived condition $(p=0.13$ (left), $p=0.21$ (right) (see Table 2)).

The main effect for reappraisal was downregulate versus maintain. However, unlike desired, an instruction to downregulate did not result in a significant activation in the ROIs for reappraisal, the dIPFC and the IOFC. The experimental method therefore did not result in a desired activation. Furthermore, sleep deprivation caused no hypothesized decrease in activity in the investigated cortical regions associated with empathy or reappraisal, the AI, aMCC or dIPFC the lOFC, respectively (see Table 2 below). 
Table 2: fMRI results for main effects and the effect of sleep deprivation. ROI = region of interest. Results represent activity signals in the ROIs, analyzed using the general linear model. Main effects represent activity during the experimental stimulation of emotion regulation and empathy. Borderline significant changes marked with bold text.

\begin{tabular}{|c|c|c|c|c|}
\hline \multicolumn{5}{|l|}{ main effect } \\
\hline ROI & Contrast & $\mathbf{t}$ & 95\% CI & $p$ \\
\hline $\mathbf{A I}(\mathbf{L})$ & Pain vs no pain & 1.7 & $-0.093,0.98$ & 0.10 \\
\hline $\mathbf{A I}(\mathbf{R})$ & Pain vs no pain & 1.5 & $-0.16,1.05$ & 0.14 \\
\hline aMCC & Pain vs no pain & 0.38 & $-0.27,1.04$ & 0.2 \\
\hline amygdala $(\mathbf{L})$ & Pain vs no pain & -0.46 & $-0.75,0.47$ & 0.64 \\
\hline amygdala (R) & pain vs no pain & -0.23 & $-0.68,0.54$ & 0.81 \\
\hline $\operatorname{dIPFC}(\mathrm{L})$ & Regulate vs maintain & 0.15 & $-1.14,1.29$ & 0.28 \\
\hline dIPFC(R) & Regulate vs maintain & -1.08 & $-0.82,0.25$ & 0.29 \\
\hline IOFC(L) & Regulate vs maintain & -0.1 & $-0.50,0.46$ & 0.92 \\
\hline IOFC(R) & Regulate vs maintain & -0.7 & $-0.48,0.23$ & 0.51 \\
\hline amygdala $(\mathbf{L})$ & regulate vs maintain & -0.60 & $-0.53,0.29$ & 0.55 \\
\hline amygdala $(\mathbf{R})$ & regulate vs maintain & -0.12 & $-0.46,0.41$ & 0.91 \\
\hline \multicolumn{5}{|c|}{ effect of sleep deprivation } \\
\hline ROI & Contrast & $\mathbf{t}$ & $95 \% \mathrm{CI}$ & $p$ \\
\hline $\mathbf{A I}(\mathbf{L})$ & pain vs no pain & -0.20 & $-0.87,0.71$ & 0.84 \\
\hline $\mathbf{A I}(\mathbf{R})$ & pain vs no pain & -0.31 & $-1.02,0.75$ & 0.75 \\
\hline aMCC & pain vs no pain & -0.21 & $-1.08,0.88$ & 0.83 \\
\hline amygdala $(\mathbf{L})$ & pain vs no pain & 1.53 & $-0.23,1.51$ & $\mathbf{0 . 1 3}$ \\
\hline amygdala $(\mathbf{R})$ & pain vs no pain & 1.30 & $-0.32,1.41$ & 0.21 \\
\hline $\operatorname{dIPFC}(\mathrm{L})$ & regulate vs maintain & 0.07 & $-1.62,1.72$ & 0.89 \\
\hline $\operatorname{dIPFC}(\mathbf{R})$ & regulate vs maintain & 0.17 & $0.72,0.85$ & 0.86 \\
\hline $\operatorname{lOFC}(\mathrm{L})$ & regulate vs maintain & 1.10 & $-0.34,1.10$ & 0.28 \\
\hline IOFC(R) & regulate vs maintain & -0.88 & $-0.39,0.15$ & 0.93 \\
\hline amygdala $(\mathbf{L})$ & regulate vs maintain & 0.97 & $-0.31,0.85$ & 0.34 \\
\hline amygdala $(\mathbf{R})$ & regulate vs maintain & 0.40 & $-0.48,72$ & 0.69 \\
\hline
\end{tabular}

\section{Discussion}

The aim of this study was to investigate effects of sleep deprivation on empathy for pain and emotion regulation through reappraisal by analyzing self-rated unpleasantness and fMRIactivity. Behaviorally, sleep deprivation caused decreased empathic responding to pictures of pain as well as increased unpleasantness reactions to neutral stimuli, as hypothesized. Emotion regulation was however not affected by sleep deprivation. In measures of neural activity, sleep deprivation caused no significant decrease in cortical activity in the investigated ROIs. Activity in the amygdalae was non-significantly increased in the sleep-deprived condition. Our fMRIfindings do therefore not support our hypothesis of decreased inhibitory signaling.

\section{Behavioral aspects}

Pictures of pain caused increased unpleasantness ratings in all conditions, confirming the effect of the pictures as negative stimuli. Unpleasantness ratings to neutral pictures were higher in the 
sleep-deprived condition, supporting the hypothesis and previous findings that reactions tend to be generally more negative when sleep deprived $(16,41)$.

\section{Empathy for pain}

Pictures of pain were rated as less unpleasant in the sleep-deprived condition. The result can be interpreted as decreased empathic responding to pictures of pain during sleep deprivation, similar to results reported by Guadagni et al (32). The result is not consistent with results reported by Tamm et al (33), who found no decrease in empathic response due to sleep deprivation. Since participants were sleep deprived through an entire night in our study and by Guadagni et al (32), the results support the theory on that Tamm et al (33) detected no change due to only subjecting their participants to partial sleep deprivation. Total sleep deprivation causes absence of all stages of sleep, including REM-sleep, which is thought to be an important factor for an individual to be emotionally affected by loss of sleep (42). Results in our study support that sleep deprivation causes decreased empathic responding, but this effect might only occur after severe sleep deprivation.

\section{Emotion regulation through reappraisal}

Participants' ability to downregulate emotional response was measured by investigating how sufficiently they were able to decrease experienced unpleasantness when given an instruction to do so. However, an instruction to downregulate had no significant effect on unpleasantness in neither of the two conditions, and it is therefore possible that our experimental method itself was not sufficiently effectful. This limits our ability to draw conclusions from comparison between sleep deprivation and full sleep. However, most participants self-reportedly had a downregulation method that can be categorized as reappraisal. Among these participants, reappraisal resulted in borderline significant decrease in unpleasantness. Hence, most participants likely did succeed to downregulate experienced unpleasantness when instructed to do so. Contrary to our hypothesis and findings in previous studies $(24,29,36)$, sleep deprivation caused no significant decrease in ability to reappraise.

Notable in previous studies are differences in study design. Shermohammed et al (37), who performed the experiment using the same method as in our study, did not detect decreased ability to downregulate negative responses after sleep deprivation. The studies in which significant effect on emotion regulation has been previously detected, are conducted using different methods. The differences create a trend that negativity bias is present in the studies 
where no effect of sleep deprivation has been found $(24,29,36)$. Negativity bias is that sleep deprivation causes neutral stimuli to be perceived as more negative, making the emotional baseline and starting point for reappraisal not fully comparable with that of the full-sleep condition (24). Negativity bias can partially explain differences in study results, since Tamm et al, Simon et al and Zhang et al did not use a method exclusively focusing on one negative emotion $(24,29,36)$. In this study and in the study by Shermohammed et al (37), behavioral results were based on ratings of a negative emotion only. Thus, the method might not be specific and sensitive enough for detecting a change in ability to regulate negative emotion.

To summarize, effects of sleep deprivation on emotion regulation is multifactorial and absence of effect in some studies can potentially be explained by methodological interactions and limitations. Even though we detected no significant change in ability to downregulate, it cannot be ruled out that participants' ability to regulate emotions was affected. Generally, behavioral results cumulatively support that when sleep deprivation is severe enough, effect on empathic responding and emotion regulation tends to be seen in subjective measures. An entire night of sleep deprivation is relatively severe and causes absence of all sleep stages, which increases the likelihood of an individual to be emotionally affected in subjective measures.

\section{fMRI: neural activity associated with reappraisal and empathy}

When it comes to neuroimaging aspects of our study, a specified interest was to investigate whether increased activity in the amygdala and decreased cortical activity would be found, as previously hypothesized, however not detected, as summarized in Table 3.

Table 3: Summary of previous fMRI-results in comparison with the hypothesis: + :increased activity in sleep deprived condition, - :decreased activity in sleep deprived condition, o: no significant difference between well-rested and sleep deprived condition

\begin{tabular}{|c|c|c|c|c|c|c|c|c|}
\hline & $\begin{array}{l}\text { According } \\
\text { to } \\
\text { hypothesis }\end{array}$ & $\begin{array}{c}\text { Yoo et al } \\
\text { (16) }\end{array}$ & $\begin{array}{l}\text { Minkel et } \\
\text { al (35) }\end{array}$ & $\begin{array}{c}\text { Tamm et } \\
\text { al }(33 \text {, } \\
36)\end{array}$ & $\begin{array}{l}\text { Simon } \\
\text { et al } \\
(24)\end{array}$ & $\begin{array}{l}\text { Guadagni } \\
\text { et al (38) }\end{array}$ & $\begin{array}{c}\text { Shermohammed } \\
\text { et al(37), }\end{array}$ & $\begin{array}{l}\text { Our } \\
\text { study }\end{array}$ \\
\hline $\begin{array}{c}\text { AI } \\
\text { (empathy) } \\
\end{array}$ & - & & & O & & - & o & O \\
\hline $\begin{array}{c}\text { mACC } \\
\text { (empathy) }\end{array}$ & - & & & O & - & o & o & $\mathrm{O}$ \\
\hline $\begin{array}{c}\text { dlPFC } \\
\text { (reappraisal) }\end{array}$ & - & - & O & o & + & & o & $\mathrm{O}$ \\
\hline $\begin{array}{c}\text { lOFC } \\
\text { (reappraisal) }\end{array}$ & - & - & o & o & & & $\mathrm{O}$ & $\mathrm{O}$ \\
\hline $\begin{array}{c}\text { amygdala } \\
\text { (unpleasantness) }\end{array}$ & + & + & + & $\mathrm{O}$ & + & & - & + \\
\hline
\end{tabular}

fMRI: activity in the amygdala 
Increased activity in the amygdala is the aspect most consistently detected in previous studies $(16,24,35)$. We found that sleep deprivation caused increased activity in the amygdalae, however statistically non-significantly ( $p=0.13$ (left), $p=0.21$ (right) (see table 2)). Hence, a trend towards increased activity was seen, but we cannot with certainty say that the detected increase was not caused by chance. Results up to date consistently show that the amygdalae are more active in a brain that is deprived of sleep. The finding is reasonable, considering the fact that the amygdalae play a key role in generation of negative emotion and behavioral results show that reactions to neutral stimuli tend to be more negative during sleep deprivation (24). Controversy around the hypothesis is caused regarding whether the enhanced reaction in the amygdalae is a result of decreased cortical inhibition. Several authors have hypothesized such causal factor $(16,34)$.

\section{fMRI: activity in cortical regions associated with reappraisal}

The main effect downregulate versus maintain was investigated to examine whether the experimental method for reappraisal resulted in an activation in the desired regions. Unlike desired, we found no significant activation of the dlPFC or the 1OFC as a response to an instruction to downregulate (see Table 2). Absence of activation in the desired ROIs could be due to not sufficient enough reappraisal, since the behavioral results were non-significant. The effect of sleep deprivation on activity in the regions does therefore not necessarily reflect reappraisal-related activity. Interpreted with this carefulness in mind, contrary to our hypothesis, no decrease in activity in the dIPFC or the 1OFC was found in the sleep deprived condition (see Table 2). Results therefore show neither activation of the ROIs when performing reappraisal, nor decreased activity in these regions during sleep deprivation.

Yoo et al (16) were among the first to investigate neural effects of sleep deprivation and their finding of weaker amygdala-PFC-connectivity during sleep deprivation generated the hypothesis (16). Tamm et al, Minkel et al and Shermohammed et al have also studied the effects of sleep deprivation on emotion regulation by investigating task-related fMRI-activity, but have not found hypothesized decrease in cortical activity during reappraisal $(16,36,37)$. Similarly, neither was decreased cortical activity detected in our study (See table 2). A limitation in the study by Yoo et al (16) is that a within-subject crossover-design was not used, as in the other studies. Individual differences might therefore have affected results. Additionally, data were not task-related fMRI, which is preferable when the aim is to investigate cognitive emotion regulation (22). On the other hand, Tamm et al (36) only restricted participants' sleep to 3 hours 
and the authors suggested that sleep deprivation might have been too weak for the hypothesized decrease in activity to occur. However, studies including an entire night of sleep deprivation have not either resulted in a detectable decrease (24, 37). Since findings supporting the hypothesis are few, it can be proposed that inhibitory signaling is not affected to a degree that changes the sum of cortical activity in the investigated ROIs. The causal factor for increased amygdala-activity and decreased ability to regulate emotions might therefore not be like previously hypothesized.

Decreased cortical inhibitory activity might be present, but not detectable on fMRI, if the decrease is compensated by increased activity in additional neural networks (14). It cannot be ruled out that task-related activity in the regions investigated had an altered composition during sleep deprivation, since activity in overlapping networks can be altered as well (24). fMRIactivity reflects the need of blood supply in a region, which is not a perfect measure of neural activity in specific networks, such as the inhibitory networks we aimed to investigate (14). Moreover, investigating activity in discrete ROIs is a method for assessing change in inhibitory activity, not a direct measure of functional connectivity (43). Thus, the fMRI-signal is no definite measure of inhibitory signaling.

Since neural activity is altered in several regions in the sleep deprived brain $(16,44)$, an alternative hypothesis could be that the state causes inability for an individual to aim attention on an emotion regulation task, leading to a decreased subjective experience of being able to regulate emotion. Such underlying mechanism could explain why decreased ability to regulate emotion can be detected in subjective measures, however not in measures of neural activity in cortical regions specific for reappraisal. Furthermore, emotion regulation requires recruitment and synchronized work of several neural networks and processes, such as memory, sensory processing and empathy (15). Thus, if a component of the process is affected, the outcome of emotion regulation is affected as well and such change could also provide an alternative hypothesis.

To summarize, conclusions cannot be drawn based on studies up to date due to inconsistent results. However, it seems that not only decreased inhibitory signaling can explain decreased ability to regulate emotion during sleep deprivation, since hypothesized decrease in cortical activity has not been detected in studies up to date. It can, however, be proposed that the amygdalae are more active during sleep deprivation, contributing to enhanced negative 
reactivity and possibly to the subjective experience of not being able to regulate emotions. What happens to inhibitory signaling between cortical regions and the amygdala might however be unlike from what previously hypothesized and needs to be studied further.

\section{fMRI: activity in cortical regions associated with empathy for pain}

To examine the effect of the pictures as a cause of a neural empathic response, the main effect was pain versus no pain. Pictures of pain caused increased activity in the AI and the aMCC in both conditions, as desired, however without statistical significance (see Table 2). We hypothesized that the regions processing empathic response are less active during sleep deprivation. However, no decrease in AI or aMCC activity was detected

Contrary to our findings, Simon et al (24) and Guadagni et al (38) have reported findings supporting the hypothesis. However, Tamm et al (36) found no decrease in activity in neural circuits of empathy in the sleep deprived condition. In this study, sleep deprivation was more severe than in the study by Tamm et al, which we hypothesized could be needed for effect to occur. Despite this difference, we found no effect of sleep deprivation on activity in the cortical ROIs. Contrary to our findings, and despite implying the same experimental method, Shermohammed et al found a non-significant trend of decrease in AI-activity in the sleep deprived condition (37). It can thus be proposed that individual differences can explain varying results and higher statistical power is needed for detecting consistent changes.

To summarize, effects of sleep deprivation on empathy seems to correlate with severity of sleep deprivation behaviorally, but in measures of neural activity results are varying. Since fMRIstudies on empathic response during sleep deprivation are few and provide inconsistent results with low statistical significance, conclusions cannot be drawn on results in studies up to date. The hypothesis, according to which regions processing empathic response are less active during sleep deprivation, remains a question to study further.

\section{Strengths and limitations}

A methodological strength of this study was that participants were sleep deprived under supervision for an entire night, making the interventional sleep deprivation theoretically more severe and controlled than in previous fMRI-studies. Additionally, conducting a study on 
healthy participants can be viewed as a strength, particularly in investigating studies on research questions previously not largely studied, as is the case with neural effects of sleep deprivation.

A small study population including exclusively healthy individuals can be viewed as a limitation, since need of sleep varies largely, especially between age groups. Young students who volunteer to participate in a sleep deprivation study might represent those least sensitive to sleep deprivation. Our participants might thus not have been as sleep deprived as desired. Furthermore, the MR-sessions were carried out in the morning, which is a time when the circadian sleepiness is not as high as during the evening, as in the design of several other studies. Additional limitations are caused by the experimental method. Sleep deprivation causes alterations in several functions, including executive functions and concentration, resulting in that scorings might not reliably represent the subjective experience of unpleasantness (45). Additionally, the pictures might not have been unpleasant enough to cause powerful emotional reactions, needed for significant success in reappraisal.

\section{Significance}

Approximately $40 \%$ of the population sleep less than recommended (9). Therefore, a large part of the population is at risk for suffering from consequences of sleep deprivation. Social acceptance of sleep-interrupting work schedules and neglect of sleepiness plays an important role in the high prevalence of sleep deprivation (46). Understanding underlying mechanisms and having evidence-based knowledge is important for consistent change in behavior and attitudes (46). This study is a part of the cumulative process of gaining knowledge on effects and mechanisms of sleep deprivation.

\section{Future Studies}

To be able to draw generalizing conclusions, a larger sample size should be investigated. Since fMRI-studies are generally resource-requiring and challenging to conduct in large scale, metaanalyses could provide results with higher statistical power. Moreover, since emotion regulation and empathy can be achieved using several methods (21), a wider range of these methods should be used in experimental methods in future fMRI-studies. In addition to implying different emotion regulation methods, both neutral and positive emotions could be stimulated and downregulated in future experimental methods in order to investigate impact of negativity bias. 


\section{Aspects of equity}

This study included exclusively young and healthy participants. Results therefore do not represent the population as a whole and in order to gain knowledge benefiting a wider range of people, the effect of sleep deprivation needs to be investigated on an older study population, as well as on individuals with underlying pathologies.

\section{Conclusions}

As hypothesized, behavioral results based on unpleasantness ratings showed that a night of total sleep deprivation caused decreased emphatic responding to pictures of pain. Likewise, as expected, neutral stimuli were perceived as more unpleasant during sleep deprivation. However, contrary to our hypothesis, participants' ability to downregulate unpleasantness through reappraisal was not significantly decreased by sleep deprivation.

No statistically significant fMRI-results were detected. Unlike hypothesized, sleep deprivation did not result in decreased cortical activity. Sleep deprivation caused expected increase in amygdala activity, however without statistical significance. The hypothesis, according to which inhibitory signaling from the cortex to the amygdala is decreased during sleep deprivation, was therefore not supported by our findings. Underlying neural mechanisms for increased activity in the amygdala and impaired emotional functioning during sleep deprivation warrant further investigation.

\section{Contributions}

The Sleepy Brain research group consisted of Mats Lekander, Gustav Nilsonne, Sandra Tamm, Torbjörn Åkerstedt, Heather Rusch, Paolo D’Onofrio and Jimmy Hermansson. I took part in collecting data together with medical student Lasse Anttila, research assistants Paolo d'Onofrio and Jimmy Hermansson, PhD Student Heather Rusch and supervisor Gustav Nilsonne. Previously, medical students Vivianne Jakobsson and Poyan Karimi have contributed to data acquisition. fMRI-data were preprocessed by Joe Wexler and Gustav Nilsonne. Data were analyzed by me with support from Gustav Nilsonne.

\section{Acknowledgements}

I am thankful to the entire research group for giving me the opportunity to take part in the Sleepy Brain Project. I would especially like to thank my supervisor Gustav Nilsonne for his 
inspiring support and guidance into scientific writing and thinking. Additionally, I am thankful to everyone who contributed to data acquisition: Gustav, Heather, Jimmy, Paolo and Lasse all have sacrificed valuable hours of sleep for this project. I would also like to thank my coordinator, Erik Pettersson, for his feedback and guidance into scientific writing.

\section{Supervisor}

Gustav Nilsonne MD, $\mathrm{PhD}$

Karolinska Institutet, Department of Clinical Neuroscience

Mail: gustav.nilsonne@ki.se

\section{References}

1. Baum KT, Desai A, Field J, Miller LE, Rausch J, Beebe DW. Sleep restriction worsens mood and emotion regulation in adolescents. J Child Psychol Psychiatry. 2014;55(2):180-90.

2. Pires GN, Bezerra AG, Tufik S, Andersen ML. Effects of acute sleep deprivation on state anxiety levels: a systematic review and meta-analysis. Sleep Med. 2016;24:10918.

3. Palmer CA, Alfano CA. Sleep and emotion regulation: An organizing, integrative review. Sleep medicine reviews. 2017;31:6-16.

4. Dorrian J, Centofanti S, Smith A, McDermott KD. Self-regulation and social behavior during sleep deprivation. Prog Brain Res. 2019;246:73-110.

5. Sheppes G, Suri G, Gross JJ. Emotion regulation and psychopathology. Annu Rev Clin Psychol. 2015;11:379-405.

6. Uchida M, Biederman J, Gabrieli JD, Micco J, de Los Angeles C, Brown A, et al. Emotion regulation ability varies in relation to intrinsic functional brain architecture. Soc Cogn Affect Neurosci. 2015;10(12):1738-48.

7. Hirshkowitz M, Whiton K, Albert SM, Alessi C, Bruni O, DonCarlos L, et al. National Sleep Foundation's updated sleep duration recommendations: final report. Sleep Health: Journal of the National Sleep Foundation. 2015;1(4):233-43.

8. Liu Y, Wheaton AG, Chapman DP, Cunningham TJ, Lu H, Croft JB. Prevalence of Healthy Sleep Duration among Adults--United States, 2014. MMWR Morb Mortal Wkly Rep. 2016;65(6):137-41.

9. Jakobsson M, Josefsson K, Jutengren G, Sandsjo L, Hogberg K. Sleep duration and sleeping difficulties among adolescents: exploring associations with school stress, selfperception and technology use. Scand J Caring Sci. 2019;33(1):197-206.

10. Scammell TE, Arrigoni E, Lipton JO. Neural Circuitry of Wakefulness and Sleep. Neuron. 2017;93(4):747-65.

11. Dang-Vu TT, Schabus M, Desseilles M, Sterpenich V, Bonjean M, Maquet P. Functional neuroimaging insights into the physiology of human sleep. Sleep. 2010;33(12):1589-603. 
12. Peña-Sarrionandia A, Mikolajczak M, Gross JJ. Integrating emotion regulation and emotional intelligence traditions: a meta-analysis. Frontiers in psychology. 2015;6:160-

13. Killgore WD, Kahn-Greene ET, Lipizzi EL, Newman RA, Kamimori GH, Balkin TJ. Sleep deprivation reduces perceived emotional intelligence and constructive thinking skills. Sleep Med. 2008;9(5):517-26.

14. Logothetis NK. What we can do and what we cannot do with fMRI. Nature. 2008;453(7197):869-78.

15. Ochsner KN, Silvers JA, Buhle JT. Functional imaging studies of emotion regulation: a synthetic review and evolving model of the cognitive control of emotion. Annals of the New York Academy of Sciences. 2012;1251:E1-24.

16. Yoo SS, Gujar N, Hu P, Jolesz FA, Walker MP. The human emotional brain without sleep--a prefrontal amygdala disconnect. Curr Biol. England2007. p. R877-8.

17. Barrett LF. The theory of constructed emotion: an active inference account of interoception and categorization. Social cognitive and affective neuroscience. 2017;12(1):1-23.

18. Saarimaki H, Gotsopoulos A, Jaaskelainen IP, Lampinen J, Vuilleumier P, Hari R, et al. Discrete Neural Signatures of Basic Emotions. Cereb Cortex. 2016;26(6):2563-73.

19. Vytal K, Hamann S. Neuroimaging Support for Discrete Neural Correlates of Basic Emotions: A Voxel-based Meta-analysis. Journal of Cognitive Neuroscience. 2009;22(12):2864-85.

20. Sotres-Bayon F, Bush DE, LeDoux JE. Emotional perseveration: an update on prefrontal-amygdala interactions in fear extinction. Learn Mem. 2004;11(5):525-35.

21. Fernandez E, Turk DC. The utility of cognitive coping strategies for altering pain perception: a meta-analysis. Pain. 1989;38(2):123-35.

22. Buhle JT, Silvers JA, Wager TD, Lopez R, Onyemekwu C, Kober H, et al. Cognitive reappraisal of emotion: a meta-analysis of human neuroimaging studies. Cerebral cortex (New York, NY : 1991). 2014;24(11):2981-90.

23. Banks SJ, Eddy KT, Angstadt M, Nathan PJ, Phan KL. Amygdala-frontal connectivity during emotion regulation. Social cognitive and affective neuroscience. 2007;2(4):30312.

24. Simon EB, Oren N, Sharon H, Kirschner A, Goldway N, Okon-Singer H, et al. Losing Neutrality: The Neural Basis of Impaired Emotional Control without Sleep. The Journal of neuroscience : the official journal of the Society for Neuroscience. 2015;35(38):13194-205.

25. Bernhardt BC, Singer T. The Neural Basis of Empathy. Annual Review of Neuroscience. 2012;35(1):1-23.

26. Lamm C, Decety J, Singer T. Meta-analytic evidence for common and distinct neural networks associated with directly experienced pain and empathy for pain. NeuroImage. 2011;54(3):2492-502.

27. Benca RM, Obermeyer WH, Thisted RA, Gillin JC. Sleep and psychiatric disorders. A meta-analysis. Arch Gen Psychiatry. 1992;49(8):651-68; discussion 69-70.

28. Vandekerckhove M, Cluydts R. The emotional brain and sleep: An intimate relationship. Sleep Medicine Reviews. 2010;14(4):219-26.

29. Zhang J, Lau EYY, Hsiao JH. Using emotion regulation strategies after sleep deprivation: ERP and behavioral findings. Cogn Affect Behav Neurosci. 2019;19(2):283-95.

30. Reddy R, Palmer CA, Jackson C, Farris SG, Alfano CA. Impact of sleep restriction versus idealized sleep on emotional experience, reactivity and regulation in healthy adolescents. J Sleep Res. 2017;26(4):516-25. 
31. Peretti S, Tempesta D, Socci V, Pino MC, Mazza M, Valenti M, et al. The role of sleep in aesthetic perception and empathy: A mediation analysis. J Sleep Res. 2019;28(3):e12664.

32. Guadagni V, Burles F, Ferrara M, Iaria G. The effects of sleep deprivation on emotional empathy. J Sleep Res. 2014;23(6):657-63.

33. Tamm S, Nilsonne G, Schwarz J, Lamm C, Kecklund G, Petrovic P, et al. The effect of sleep restriction on empathy for pain: An fMRI study in younger and older adults. Scientific reports. 2017;7(1):12236-.

34. Walker MP. The Role of Sleep in Cognition and Emotion. Annals of the New York Academy of Sciences. 2009;1156(1):168-97.

35. Minkel JD, McNealy K, Gianaros PJ, Drabant EM, Gross JJ, Manuck SB, et al. Sleep quality and neural circuit function supporting emotion regulation. Biol Mood Anxiety Disord. 2012;2:22.

36. Tamm S, Nilsonne G, Schwarz J, Golkar A, Kecklund G, Petrovic P, et al. Sleep restriction caused impaired emotional regulation without detectable brain activation changes-a functional magnetic resonance imaging study. Royal Society open science. 2019;6(3):181704-.

37. Shermohammed M, Kordyban LE, Somerville LH. Examining the Causal Effects of Sleep Deprivation on Emotion Regulation and Its Neural Mechanisms. Journal of Cognitive Neuroscience. 2020:1-12.

38. Guadagni V, Burles F, Ferrara M, Iaria G. Sleep quality and its association with the insular cortex in emotional empathy. Eur J Neurosci. 2018;48(6):2288-300.

39. Vuorre M. How to analyze visual analog (slider) scale data? https://vuorre.netlify.app/: Matti Vuorre; 2019 [updated 2019-11-07]. Available from: https://vuorre.netlify.app/post/2019/02/18/analyze-analog-scale-ratings-with-zero-oneinflated-beta-models/.

40. Gottlieb DJ, Ellenbogen JM, Bianchi MT, Czeisler CA. Sleep deficiency and motor vehicle crash risk in the general population: a prospective cohort study. BMC Med. 2018;16(1):44.

41. Walker MP. The role of sleep in cognition and emotion. Ann N Y Acad Sci. 2009;1156:168-97.

42. Walker MP, van der Helm E. Overnight therapy? The role of sleep in emotional brain processing. Psychol Bull. 2009;135(5):731-48.

43. Deleus F, Van Hulle MM. Functional connectivity analysis of fMRI data based on regularized multiset canonical correlation analysis. J Neurosci Methods. 2011;197(1):143-57.

44. Krause AJ, Prather AA, Wager TD, Lindquist MA, Walker MP. The Pain of Sleep Loss: A Brain Characterization in Humans. J Neurosci. 2019;39(12):2291-300.

45. Lowe CJ, Safati A, Hall PA. The neurocognitive consequences of sleep restriction: A meta-analytic review. Neurosci Biobehav Rev. 2017;80:586-604.

46. Peach HD, Gaultney JF, Ruggiero AR. Direct and Indirect Associations of Sleep Knowledge and Attitudes With Objective and Subjective Sleep Duration and Quality via Sleep Hygiene. J Prim Prev. 2018;39(6):555-70. 